Editorial (2)

\title{
Good enough for Iganga?
}

\author{
Graham Dukes
}

\begin{abstract}
After only seven hours in Iganga province, it was time to climb once more into the jeep and take the road back to Entebbe, a hotel, a shower, the daily malaria tablet. Seven hours is not a great deal of time to form a view of another world; so why put pen to paper this evening? Wait, surely, until you have seen more widely, listened more carefully, considered more fully. Yet all the same there is some merit in writing when the impressions are still fresh, the indignation still warm, when there has been no time to adjust to a new concept of medical normality, no opportunity to compromise. Just now and then, Iganga needs to be looked at with eyes fresh from the West. But my colleague in the back of the jeep was already shaking his head, patting my arm paternally. "The sort of health care that you have seen here" he said, "is all you can expect, perhaps more. It is quite good enough for Iganga".

In many ways, Uganda is a far from depressing place. Indeed, whatever its problems, it is a country with a great deal of infectious good humour and spirit. Once brought to the antechamber of ruin by Idi Amin it is climbing bravely and cheerfully back under the honest statesmanship of President Museveni to something which promises to approach the normality of two decades ago and then rise beyond it. On a second or third visit, the sensation of progress by the month and the year is unmistakable. Improvisation is everywhere; Makere University has just this year delivered its first class of qualified pharmacists - trained (and well trained) in a school where almost every piece of equipment which one would think is needed seems to be absent, defective, or out of date. Countries with that spirit deserve whatever help can be given them; by and large it will be accepted with dignity and used with good sense. There is no secret as to the Danish hand and the Danish money in the Uganda Essential Drugs Management Programme which is still the backbone of the country's medical supply system; but the Uganda role becomes stronger by the day, and however many days it may take, there will one day be no more need for Danes or kroner. For both parties, that is the most rewarding thing of all.

If this is the bright and hopeful side of health care in a "developing" country in the best sense of the word, the shadow side must be set against it. This is not the place to dwell on AIDS; it is a scourge which overshadows a great part of the population, but AIDS is qualitatively as formidable in the West as it is here, and the lack of knowledge to combat it is unhappily still universal. The present point is that in those fields of health care where there is knowledge in plenty but a
\end{abstract}


fearfully unfair distribution across the world of the means to implement it one has to beware of becoming complacent. Magnificent work has been done, and much of it continues, but just here and there people are beginning to stand on their laurels, and it is too early for that. Consider Iganga province.

One can have every admiration for the fact that a dispenser with two years of training and a dozen drugs on his table manages to do so much good, but there are occasions when his resources - including his knowledge as to when to a refer a patient to a doctor in town - will be insufficient. One cannot relax when pentothal is repeatedly out of stock in a hospital. The Ugandan midwife has become skilled in matters which in some parts of the West have been voraciously and unnecessarily claimed as the province of the gynaecologist with ten years of specialist training, but in a complicated breech delivery she may be out of her depth. People are still turning to the quack, the drug pedlar and the profiteer because everything else has failed them. In a world where there is plenty of knowledge and experience to avoid the harm which these situations do, the fact that they are occurring all the time is not good enough. The World Health Organization's ideal of health for all in fact provides the standard one needs, if only one takes the trouble to understand it; it does not mean that everyone will be healthy, but that the world's knowledge and resources must be exploited to a point where avoidable ill-health and suffering are eliminated. It is obvious that Iganga cannot afford a first-class ticket to the standards of Western countries which have five hundred dollars and more to spend on health per inhabitant per year, but when one sees what a mere one dollar a day can do (a point to which we shall return in a moment) one should be able to define an attainable golden mean for the next decade.

Like a great many other places in Africa, Iganga benefits from drugs distributed through a "kit" system. That system - periodically providing large boxes of drugs in a standard variety to each centre in a predesigned assortment - created a drug supply in a situation where there had previously been none, and for that one can be thankful. The deficiencies which the kit system has are in the details, not in the concept. When drugs arrive at a dispensary, which is as likely as not to have been out of stock for a while - that is what we saw in Bunyira - the word goes round, and a flood of patients arrives to overwhelm the staff. The size of a kit, quite simply, is calculated on the assumption that every patient will be treated only for a day and a half; that may be enough; often it is not. The contents of the kit are designed to meet the average need of a centre; and clearly no centre is entirely average. The kits thus provide only a rough-and-ready solution; in Iganga there is too little pentothal in them to meet local needs and often too little injectable penicillin, while the ergometrine which the kits contain may end up in centres which have no obstetric patients to treat. In Namubngalwe, which attracts patients with sleeping sickness, there is a special supply of drugs for that purpose but nothing for the secondary ailments which often accompany it. Bugiri Hospital is supposed to conduct operations, yet there has been no pentothal for more than a year because of hold-ups at some central point, perhaps the National Treasury; how many operations can wait for a year? Once again: none of this is the fault of the generous Danes, and very little of what goes wrong can be pinned down to any 
particular fault in Uganda. The fact is simply that one is struggling along at a minimum level of care, that the care provided naturally and unavoidably fluctuates, and that whenever the fluctuation is in a downwards direction the care becomes inadequate; people suffer, or people die.

\section{Cost recovery?}

A question which soon arises is whether, if the government cannot provide all the health care which is needed, the public itself should not be called upon to make its contribution, perhaps buying from the private sector what the public health system cannot contrive to give them. As the World Bank, the great proponent of cost recovery, never tires of saying, there is a great difference between finding that there is little money in the public's pocket and assuming that there is none at all. It is a well documented fact that where people have any money at all, they will give health and drugs a high priority in their spending. All the same, the free market principle in its most absolute form can be a dangerous toy in the hands of those who have not grown up with it. The need for caution arises at several levels. To begin with, the principle of the social safety net must not be undermined; there are the truly indigent who have neither income or money of their own nor families to provide for them; they will always need full support from the state, without compromise. Secondly, the failure of the free market to serve the entire population in the past was the very reason for the institution of state-controlled drug services; whatever their deficiencies they are better than a private sector which is content to live from selling high-priced drugs only to the affluent in the cities; the private sector needs a lot of cajoling if it is to do better in the future.

Subject to those and similar reservations, there is a lot to be said for introducing patient contributions in some form, perhaps ideally within the public sector itself. The Gross National Product of Uganda in 1988 was $\$ 280$ per head per year; plenty of people have estimated that the basic drug requirements of a population can, by astute buying on the world generic market, be met for an average of only $\$ 1$ per head per year. Though the actual expenditure is naturally unevenly spread, this suggests that the level of costs is not so formidable that the population cannot cover at least a part of them. In Iganga, as elsewhere, one also runs into the popular belief that "free" drugs are necessarily third-rate drugs, and that what one buys in the drug shop for one's hard earned money is better; spending even a little money on the drugs which the State provides can therefore have a useful placebo effect of its own.

If a payment scheme is to be introduced, however, there are some right and some wrong ways to do it, and by trial and error much of Africa has been discovering them. Uganda initially chose the wrong way; a state body decreed that drugs should in part be paid for, the level of payments was set, a mechanism was devised to ensure that the money would flow to the centre. The system collapsed almost before it was born, partly because of political opposition but also because of a clear lack of faith in bureaucratic mechanisms; what starts as a meaningful 
contribution to improve the quality of care can quickly and easily degenerate into a mere tax levied by the exchequer. After the collapse, however, something very interesting happened, in that a great many local health centres and dispensaries introduced their own patient contribution schemes. It was local democracy at its best; the committees of professionals and patients who run the centres levied the charges themselves, deciding on the level of payment, the people to be exempted from charges, the purposes for which the money was to be used and the way in which the accounts were to be kept. In the one village in Iganga, as I could see for myself, the very small funds which were built up served to buy from the private sector drugs which were currently out of stock in the state system; in another some simple equipment was acquired, in yet another the pitiful salaries of some of the health workers were supplemented. The development goes on; it is perhaps a series of small steps in the right direction, with people using their money in sensible ways to meet their own real needs. If bureaucracy were to pounce upon it and seek to centralize it again it might be smothered; it is a tender seedling which must be allowed to grow quietly if it is ever to flower.

\section{Conclusion}

All these considerations bring one back however, to the thought which sparked this paper - the high-nosed western notion, expressed by my colleague in the jeep, that a very minimal level of health care is good enough for these splendid people. What is good enough? In the process of development there are fields where one can define a clear minimum - a point beyond which the help provider can relax a little. Where one is dealing with food, one can be complacent as soon as there is no more hunger; greater variety will surely follow. In housing, it may initially be sufficient that everyone has a watertight roof of some sort over his head, even if it is not a very good roof. Even in the case of vaccines one can be satisfied where there are no more epidemics; with economic growth, more convenient and more efficient vaccines will come naturally, just as will larger T.V. screens and bettersmelling soap. But at what point can one be satisfied that drug care - or, for that matter, diagnostics, surgery and equipment - are good enough, and that one can relax? Is even the availability of a basic list of "essential drugs" enough?

One clue lies, perhaps, in the entire question of safety. Minimal medicine can be risky medicine. The conscientious medical assistant may in ninety percent of cases be as adequate as a full-trained doctor, but the corollary of that is that in the remaining ten he will not. Take the case of drugs; it is good that in much of developing Africa thiacetazone is to hand to treat tuberculosis at low cost, but let us not forget that it is so toxic to every system that in the West it is obsolete. Alongside the cast-off drugs from the West there are the problems (and opportunities) posed by the largely unexplored drugs of Africa itself. One cannot be in that continent very long without becoming convinced that there is a great deal of wisdom in the traditional medicine of the people which deserves to be taken seriously. There is no need to glorify traditional medicine as some people do, as if 
it represents a standard greater than that of current science. What it does bring with it is a great deal of accrued common-sense, a massive collection of empiric and readily available solutions to problems in health care which at some points probably are better or safer remedies than current western drug therapy and deserve to be taken seriously. But it also carries risks, which have commonly not been thoroughly studied and defined; some of the most potent carcinogens and teratogens have been found in plant medicines. The risk in the present situation is that traditional medicine will increasingly become the backwater of health care, a means to which one has resort only where scientific medicine is topographically or financially out of reach. W.H.O. has done something to ensure that traditional healing is studied, but the field has received only a fraction of the attention which it deserves if the best elements in it are to be exploited and the weakest eliminated.

A great many people can be pleased with what aid and self-help has achieved in bringing care to places like Iganga. Pleased, but not satisfied. One must not be sure to soon that one has reached a plateau on the road where the climb is essentially over. No-one in the West would tolerate in his own country the conclusion that health care is now as good or as safe as it needs to be and it would be condescending indeed to settle for that view in a developing country. There is always reason to try and do better, pressing effort and expenditure to the limit of what can be afforded, and then rather further. At a given time and place the argument may turn on whether a country can afford a second cancer irradiation centre, at another on whether it can afford to put a doctor in every town, but it is the same argument at different stages on the road. If one gives up on the doctor, one will never even come within sight of even the first cancer centre. In health care there will always be a struggle to find the means to render services better and safer, and it is perfectly satisfactory that this should be so; we continue to make the effort because the challenge remains.

Entebbe, Uganda 